\begin{tabular}{cc|c}
\hline Tar. Bil. Der. & Journal of Agricultural Sciences \\
& $\begin{array}{c}\text { Dergi web sayfası: } \\
\text { www.agri.ankara.edu.tr/dergi }\end{array}$ & Journal homepage: \\
& www.agri.ankara.edu.tr/journal
\end{tabular}

\title{
Saros Körfezi (Kuzey Ege Denizi, Türkiye)'nden Avlanan Benekli Pisi Balığının (Lepidorhombus boscii Risso, 1810) Bazı Üreme Özellikleri
}

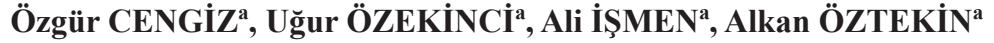 \\ ${ }^{a}$ Çanakkale Onsekiz Mart Üniversitesi, Deniz Bilimleri ve Teknolojisi Fakültesi, Terzioğlu Kampüsü, Çanakkale, TÜRKIYE
}

\section{ESER BILGISII}

Araştırma Makalesi

DOI: 10.1501/Tarimbil 0000001329

Sorumlu Yazar: Özgür CENGİZ, E-posta: ozgurcengiz17@gmail.com, Tel: +90 (286) 2180018 / 2034

Geliş Tarihi: 20 Ocak 2014, Düzeltmelerin Gelişi: 23 Haziran 2014, Kabul: 10 Temmuz 2014

\begin{abstract}
ÖZET
Bu çalışma Eylül 2006 - Eylül 2008 tarihleri arasında Saros Körfezi (Kuzey Ege Denizi, Türkiye)’nde gerçekleştirilmiştir. Balık örnekleri 0 - $500 \mathrm{~m}$ arası derinliklerde ayda bir defa torba ağ gözü açıklığı $44 \mathrm{~mm}$ olan ticari dip trolü ağı kullanılarak toplanmıştır. Benekli pisi balığının (Lepidorhombus boscii Risso, 1810) üreme döneminin Şubat-Mayıs ayları arasında olduğu belirlenmiştir. İlk üreme boyu dişi bireyler için $14.9 \mathrm{~cm}$, erkek bireyler için ise $15.3 \mathrm{~cm}$ olarak saptanmıştır. Türün mutlak yumurta verimliliği - toplam boy, mutlak yumurta verimliliği - toplam ağırlık ve mutlak yumurta verimliliği - yaş arasındaki ilişkiler sırasıyla $\mathrm{F}=1.487 \times \mathrm{TL}^{3.22}, \mathrm{~F}=264.39 \times \mathrm{TW}+14.103$ ve $\mathrm{F}=12.207 \times \mathrm{A}$ 11.279 olarak tespit edilmiştir. Bu çalışma benekli pisi balığının Türkiye sularında bazı üreme özelliklerine ilişkin ilk verileri içermektedir.
\end{abstract}

Anahtar Kelimeler: Benekli pisi balığı; Üreme özellikleri; Saros Körfezi; Kuzey Ege Denizi

\section{Some Reproductive Characteristics of Four-spotted megrim (Lepidorhombus boscii Risso, 1810) from Saros Bay (Northern Aegean Sea, Turkey)}

\section{ARTICLE INFO}

Research Article

Corresponding Author: Özgür CENGİZ, E-mail: ozgurcengiz17@gmail.com, Tel: +90 (286) 2180018 / 2034

Received: 20 January 2014, Received in Revised Form: 23 June 2014, Accepted: 10 July 2014

\begin{abstract}
This study was carried out between September 2006 - September 2008 in Saros Bay (Northern Aegean Sea, Turkey). The fish samples were collected using a commercial bottom trawl net with $44 \mathrm{~mm}$ codend mesh size at depths ranging from 0 to $500 \mathrm{~m}$ The spawning period of four-spotted megrim (Lepidorhombus boscii Risso, 1810) occurred between February and May. First sexual maturity length was $14.9 \mathrm{~cm}$ for females and $15.3 \mathrm{~cm}$ for males. Absolute fecundity - total length, absolute fecundity - total weight and absolute fecundity - age relationships were estimated as $\mathrm{F}=1.487 \times \mathrm{TL}^{3.22}$, $\mathrm{F}=264.39 \times \mathrm{W}+14.103$ and $\mathrm{F}=12.207 \times \mathrm{A}-11.279$, respectively. This study includes first data on some reproductive characteristics of four-spotted megrim for Turkish waters.

Keywords: Four-spotted megrim; Reproductive characteristics; Saros Bay; Northern Aegean Sea
\end{abstract}




\section{Giriş}

Bir balık türünün üreme zamanı ve süresi, ilk üreme boyu, yumurta verimliliği ve cinsiyet oranı gibi bilgilerinin bilinmesi türün stok durumu hakkında daha çok bilgi edinilmesi açısından yarar sağlamaktadır (Murua et al 2003).

Benekli pisi balığı (Lepidorhombus boscii Risso, 1810) Scophthalmidae familyasının ticari değere sahip bir üyesidir. Genellikle çamurlu ve yumuşak dip yapısına sahip 7 ile $800 \mathrm{~m}$ derinlikler arasında yaşamını sürdürmekte (Nielsen 1986) ve 20 cm'ye ulaştığ1 zaman ticari değer kazanmaktadır (Vassilopoulou 2000). Dünya denizlerinde Kuzeydoğu Atlantik, Güney İngiliz Adaları, Cape Bojodor ve Batı Sahara bölgelerinde (Bauchot 1987), Türkiye'de ise Marmara, Ege ve Akdeniz kıyılarında dağılım göstermektedir (Bilecenoğlu et al 2002).

Benekli pisi balığının biyolojisine yönelik olarak dünyanın farklı bölgelerinde farklı araştırıcılar (Grubisic 1962; Fuertes 1978; Bello \& Rizzi 1987; Papaconstantinou et al 1989; Mannini et al 1990; Castilho et al 1993;Santos 1994; Stergiou \& Politou 1995; Vassilopoulou et al 1997; Vassilopoulou \& Ondrias 1999; Robson et al 2000; Vassilopoulou \& Haralabous 2008) tarafından yapılmış çalışmalar bulunmasına karşın, Türkiye'deki çalışmalar sınırlı sayıdadır. Bu çalışmalarda; JICA (1993) ve Cengiz et al (2014a) Kuzey Ege Denizi'nde stok büyüklügünü, Bostanc1 \& Polat (2008) ve Cengiz et al (2012a) otolit yapısın1, Cengiz et al (2013) büyüme parametrelerini ve Cengiz et al (2014b) sömürülme değerlerini incelemişlerdir. Türün Saros Körfezi'ndeki varlığı ise Cengiz et al (2011) tarafından bildirilmiştir.

T.C. Gıda Tarım ve Hayvancılık Bakanlığı'nın yayınladığı 3/1 Numaralı Ticari Amaçlı Su Ürünleri Avcılığını Düzenleyen Tebliğ (Tebliğ No: 2012/65)' de benekli pisi balığına ilişkin herhangi bir düzenleme bulunmamaktadır. Bu bağlamda, bu ön çalışmaile Saros Körfezi'nden avlanan benekli pisi balığının ilk üreme boyu, üreme zamanı ve yumurta verimliliği saptanarak balıkçılık yönetimine türün sürdürülebilirliği için gerekli önerilerin sunulması ve sonraki çalışmalara kaynak teşkil etmesi amaçlanmıştır. $\mathrm{Bu}$ çalışma Türkiye sularındaki benekli pisi balığının üreme özelliklerine ilişkin ilk verileri içermektedir.

\section{Materyal ve Yöntem}

\section{1. Çalışma alanı ve balıkların örneklenmesi}

Ege Denizi'nin kuzeydoğusunda yer alan Saros Körfezi, güneyde Gelibolu Yarımadası ile kuzeyde Trakya kıyıları arasında bulunan ve yaklaşık olarak $60 \mathrm{~km}$ içeri sokulan üçgen şeklinde bir körfezdir. Körfeze, başta Meriç ve Kavak nehirleri olmak üzere farklı akarsulardan sürekli bir sediment ve tatlısu girdisi olmakta (Sar1 \& Çağatay 2001) ve körfezin besleyici elementler açısından verimliliği artmaktadır. Ayrıca, Saros Körfezi, tuzluluk ve besleyici elementler yönünden, boğazlar sistemi aracılığıyla soğuk ve az tuzlu Karadeniz sularının etkisi altındadır (Zodiatis \& Balopoulos 1993). Körfez, 2000 yılından beri trol avcılığına kapalıdır.

Balık örnekleri Saros Körfezi’nde Eylül 2006 Eylül 2008 döneminde ayda bir defa 0-500 m arası derinliklerde, torba ağ göz açıklığı $44 \mathrm{~mm}$ olan ticari dip trolüyle toplanmıştır. $\mathrm{Bu}$ tarihler arasında toplam 100.2 saat olmak üzere 184 trol çekimi yapılmıştır (Şekil 1). Soğuk muhafaza koşullarında laboratuvara getirilen örneklerin toplam boy, toplam ağırlık ve gonad ağırlı̆̆ ölçümleri ile gonadların olgunluk safhalarına ilişkin incelemeler ve yaş tayinleri laboratuvarda yapılmıştır. Balıkların boyları $\pm 1 \mathrm{~mm}$, vücut ağırlıkları $\pm 0.01 \mathrm{~g}$, gonad ağırlıkları ise $\pm 0.0001 \mathrm{~g}$ hassasiyette belirlenmiştir.

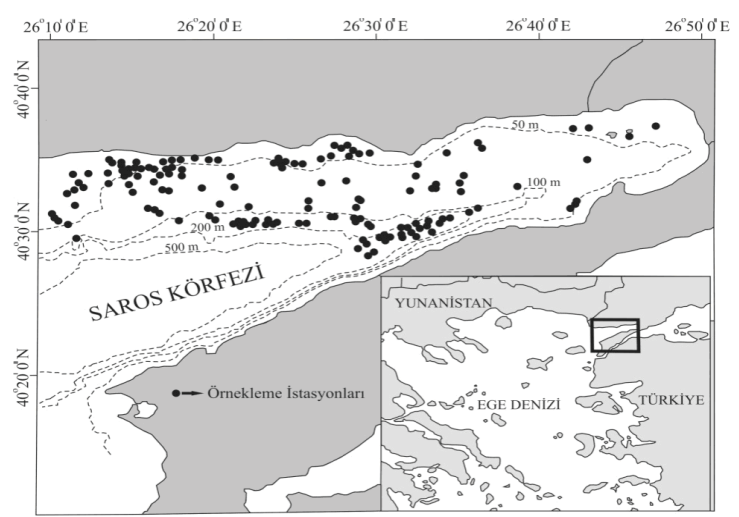

Şekil 1- Saroz Körfezi ve örnekleme istasyonları

Figure 1-Saros Bay and sampling stations 


\subsection{Yaş okumaları}

Yassı balıklarda otolit merkezi kör bölge olarak adlandırılan otolitte (Şekil 2) ortaya, gözlü bölge olarak isimlendirilen otolitte (Şekil 3) ise posterior bölgesine yakın bir konumda bulunmaktadır. Yaş halkaları kör bölge otolitinde hem anterior hem de posterior bölgesinde tespit edildiğinden yaş tayininde kör bölge otoliti kullanılmıştır (Cengiz et al 2012a; 2012b; 2014c).

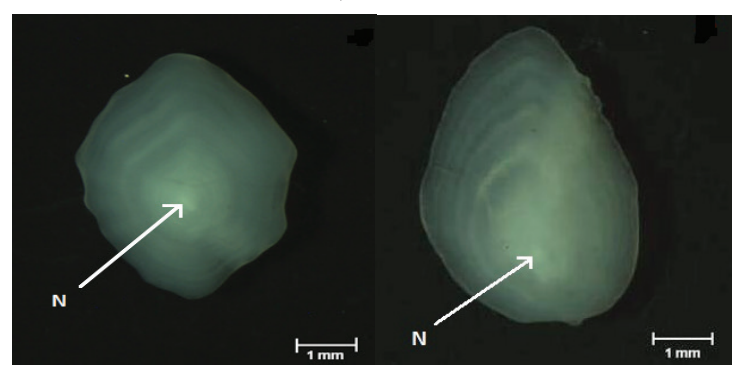

Şekil 2- Kör bölge otoliti (N: Nükleus) Şekil 3Gözlü bölge otoliti (N: Nükleus)

Figure 2- Blind side otolith (N: Nucleus) Figure 3Ocular side otolith (N: Nucleus)

Otolitler, yaş tayini için önce $\% 5$ 'lik $\mathrm{HCl}$ ve daha sonra \% 3 'lük $\mathrm{NaOH}$ çözeltisinde temizlenene kadar bekletilip saf sudan geçirildikten sonra da kurutulmuştur. Yaş tayini için otolitler, bütün olarak, içerisinde su bulunan siyah zemine sahip bir kapta üsten aydınlatma ile 1şı mikroskobunda okunmuştur (Cengiz et al 2013).

\subsection{Cinsiyet tayini ve ilk üreme boyu}

Balıklarda gonadların ayrımı ancak belirli bir gelişme döneminden sonra mümkündür. Çoğunlukla testisler aynı gelişme derecesindeki ovaryumlara kıyasla daha küçük, yassı, beyazımsı renkte ve opak olup, diş çeperlerinde gözle görülebilen fazla kan damarı bulundurmazlar. Ovaryumlar ise daha büyük olup sarımsı renktedir ve üzerinde daha fazla kan damarları vardır (Erkoyuncu 1995).

Balıkların cinsiyeti ve eşeysel olgunlukları makroskobik olarak belirlenmiştir. Gonad gelişim safhaları Gunderson (1993)'e göre saptanmıştır.

1.safha: Olgunlaşmamış safhadır. Çıplak gözle eşey ayrımı yapmak neredeyse imkansızdır.
Gonadlar, genellikle vücut boşluğunun 1/3'lük kısmını kapsamaktadır.

2.safha: Dinlenme safhasıdır, oositler çıplak gözle görülmez. Dişilerin ovaryumu pembe renkli, erkeklerinki beyazımsıdır.

3.safha: Olgunlaşma aşaması olup gonadlar portakal renklidir, oositler çıplak gözle görülebilir. Gonadlar vücut boşluğunun 2/3'ünün kapsar.

4.safha: Yumurtalar olgunlaşmış olup iri ve saydamdır. Ovaryumlar turuncu veya pembe renkli olup gelişmiş kan damarlarıyla çevrilmiştir.

5.safha: Yumurtalar boşalmıştır. Ovaryumlar koyu renkli veya saydam halde olup içinde birbirlerine yapışmış olgun yumurtalara rastlanılabilir. Testisler kanlı ve sarkık bir haldedir.

İlk üreme boyunu $\left(L_{50}\right)$ tahmin etmek için ikinci, üçüncü ve dördüncü gonad safhalarının göründüğü aylardaki balıklar $1 \mathrm{~cm}$ aralıklarla boy sınıflarına ayrılmış ve her boy sınıfına karşılık gelen olgun balık oranına $P=1 / 1+\exp \left[-r\left(L-L_{50}\right)\right]$ şeklindeki doğrusal olmayan en küçük kareler regresyon tekniği uygulanmıştır. Lojistik eşitlikteki; $P$, her boy sınıfindaki olgun balıkların oranın (\%); $r$, olgunluk eğrisinin eğimini ve $L_{50}$, balıkların \% 50'sinin ürediği boyu ifade etmektedir (King 1995).

\subsection{Gonadosomatik indeks (GSI)}

Dişi ve erkek bireylerin üreme zamanını gösteren bu indeksin hesaplanmasındaAvşar (2005)' in önerdiği eşitlik kullanılmıştır;

GSI (Gonadosomatik indeks) $=($ Gonad Ağırlığı /

Vücut ağırlığ1 - Gonad A ̆ğılığı) $\times 100$

\subsection{Mutlak yumurta verimliliği (fekondite)}

Yumurta verimliliğini saptamak için üreme mevsiminde olgunlaşmış ve yumurtalarını dökmemiş olan dişi bireylerin dördüncü gonad safhasındaki ovaryumları kullanılmıştır. Yumurta verimliliği Bagenal (1978)'in önerdiği gravimetrik yöntemle 
saptanmıştır. $\mathrm{Bu}$ amaçla ovaryumların anterior, orta ve posterior bölümlerinden alınan alt örnekler gilson çözeltisine (100 mL \% 60'llk etil alkol, $800 \mathrm{~mL}$ saf su, $15 \mathrm{~mL} \% 80^{\prime}$ lik nitrik asit, $18 \mathrm{~mL}$ glacial asetik asit ve $20 \mathrm{~g}$ cıva klorür) konulmuş, 48 saat aralıklarla çalkalanmış ve yumurtaların bağ dokudan ayrılması sağlanmıştır. Yumurtaların sayımı stereo mikroskopta yapılmış ve ortalama yumurta sayısı aşağıdaki gibi hesaplanmıştır (Avşar 2005);

$\mathrm{F}=\mathrm{n} \times(\mathrm{G} / \mathrm{g})$

Burada; F, mutlak yumurta verimliliği; G, gonad ağırlığını (g); g, alt örneğin ağırlığını (g); n, alt örnekteki yumurta sayısı (adet)'dır.

Mutlak yumurta verimliliği - toplam boy, mutlak yumurta verimliliği - toplam ağırlık ve mutlak yumurta verimliliği - yaş arasındaki ilişkiler ise aşağıdaki denklemlerden bulunmuştur (Avşar 2005).

$\mathrm{F}=\mathrm{a} \times \mathrm{TL} L^{\mathrm{b}}$

$\mathrm{F}=\mathrm{a}+\mathrm{b} \times \mathrm{TW}$

$\mathrm{F}=\mathrm{a}+\mathrm{b} \times \mathrm{A}$

Burada; F, mutlak yumurta verimliliği; TL, toplam boyu (cm); TW, toplam ağırlığı (g); A, yaşı (yı1); a ve $b$, regresyon sabitleridir.

\section{Bulgular ve Tartışma}

\subsection{Dişi:erkek oranı ve boy dağılımı}

Eylül 2006 - Eylül 2008 döneminde örneklenen 2224 adet benekli pisibalığından 788 adedi alt örnek olarak alınmıştır. Alt örnekte 553 (\% 70.2) bireyin dişi, 235 (\% 29.8) bireyin ise erkek olduğu belirlenmiş ve dişi: erkek oranı 1: 0.42 olarak hesaplanmıştır. Dişi ve erkek bireylerin sayıları arasındaki fark önemli bulunmuştur $\left(x^{2} ; \mathrm{P}<0.05\right)$. Diğer araştırıcılar tarafından saptana dişi:erkek oranları Çizelge 1'de verilmiş̧ir.

Dişi:erkek oranları arasındaki farklılıklar, dişi ve erkek bireyler arasındaki büyüme ve ölüm oranlarında görülen farklılıklar (İnnal 2010) ile üreme ve göç (Avşar 2005) gibi faktörlerden kaynaklanabilir. Dişi bireylerin boyu 11.4 - 40.8 $\mathrm{cm}$ ağırlı̆̆ 1 ise $10.74-679.18 \mathrm{~g}$ arasında değişim göstermiştir. Erkek bireylerin boyunun 10.9 - 30.3 $\mathrm{cm}$ ağırlı̆̆ının ise $9.88-271.18 \mathrm{~g}$ arasında değiştiği saptanmıştır.

\subsection{Illk üreme boyu}

$\mathrm{Bu}$ çalışmada benekli pisi balığının ilk üreme boyu dişi bireyleri için $14.9 \mathrm{~cm}$ (2 yaş), erkek bireyler için ise $15.3 \mathrm{~cm}$ ( 2 yaş) olarak belirlenmiştir. Benekli pisi balığının dişi ve erkek bireylerine ait ilk üreme boyları Şekil 4'de verilmiştir. Bu çalışmada ve bundan önceki çalışmalarda saptanan ilk üreme boylarının karşılaştırılması Çizelge 2'de verilmiştir.

Bu çalışma ile bundan önceki çalışmalar arasında ilk üreme boylarında gözlenen farklılıkların olası sebepleri bölgeler arasındaki besin ve sicaklık değişikliklerine (Nikolsky 1963), genetik faktörlere (Wootton 1998), avlama baskısına ve av araçlarının seçiciliğine (Jennings et al 2001) ve ilk üreme boyunun tespitinde kullanılan farklı yöntemlere (Froese \& Binohlan 2000) bağlanabilir.

\section{Çizelge 1- Benekli pisi balığının (Lepidorhombus boscii) diğer araştırıcılar tarafından bildirilen dişi:erkek oranları}

Table 1- Female:male rates of four-spotted megrim (Lepidorhombus boscii) reported by other authors

\begin{tabular}{llc}
\hline Yazar(lar) & Bölge & Dişi:Erkek oranı \\
\hline Bello \& Rizzi (1987) & Güney Adriatik & $1: 1.12$ \\
Castilho et al (1993) & Portekiz kıyıları & $1: 1.13$ \\
Santos (1994) & Portekiz kıyıları & $1: 1.11$ \\
Vassilopoulou \& Ondrias (1999) & Doğu Akdeniz (Yunanistan) & $1: 0.78$ \\
Robson et al (2000) & İrlanda kıyıları & $1: 0.71$ \\
Teixeria et al (2010) & Portekiz kıyıları & $1: 0.52$ \\
Bu çalışma & Saros Körfezi (Türkiye) & $1: 0.42$ \\
\hline
\end{tabular}




\subsection{Gonadosomatik indeks (GSI)}

Benekli pisi balığının GSI değerleri aylara göre dişi bireyler için 0.43 ile 5.86 arasında, erkek bireyler için 0.24 ile 1.28 arasında değişim göstermiştir. GSI değerleri 2006 ve 2007 yılının Aralık ayında artmaya başlamış, Şubat aylarında maksimum, Eylül aylarında ise minimum olmuştur. Bu nedenle, benekli pisi balığının Şubat ayından başlayarak Mayıs ayına kadar yumurtladığı saptanmıştır (Şekil

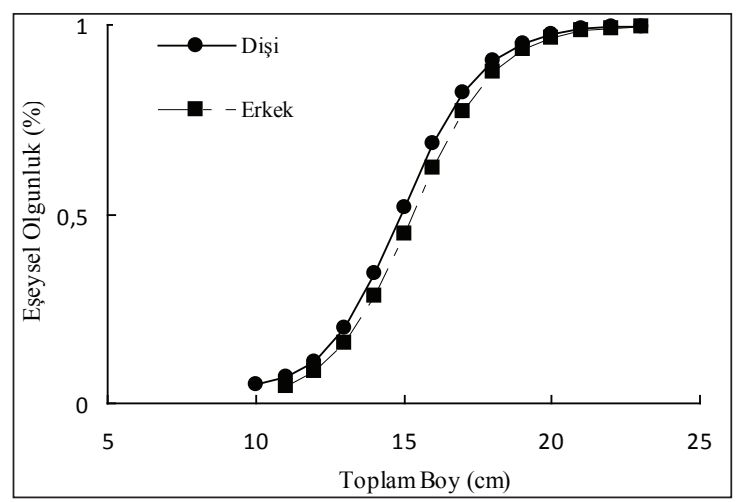

Şekil 4- Saros Körfezi’nden avlanan benekli pisi balığının (Lepidorhombus boscii) dişi ve erkek bireylerinin ilk üreme boyları

Figure 4- Lengths at first maturity for female and male four-spotted megrim (Lepidorhombus boscii) from Saros Bay
5). Benekli pisi balığının bu çalışma ile önceki çalışmalarda üreme dönemlerinin mukayesesi Çizelge 3'de sunulmuştur.

Benekli pisi balığının üreme dönemindeki farklılıklar bölgeler arasındaki biyotik ve abiyotik faktörlerin farklılığından kaynaklanmış olabilir. Wootton (1990) balıkların üremesini etkileyen en önemli abiyotik faktörün su sicaklığı olduğunu bildirmiştir.

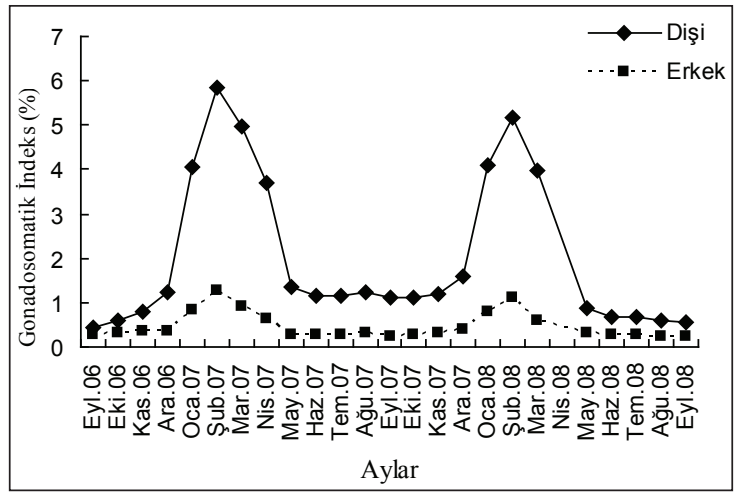

Şekil 5- Saros Körfezi'nden avlanan benekli pisi balığının (Lepidorhombus boscii) dişi ve erkek bireyleri için aylık GSI değerleri

Figure 5-Monthly gonadosomatic index (\%) values for female and male four-spotted megrim (Lepidorhombus boscii) from Saros Bay

Çizelge 2- Benekli pisi balığının (Lepidorhombus boscii) bu ve diğer çalışmalarda saptanan ilk üreme boylarının karşılaş̧ırırılması

Table 2-Comparison of the lengths at first maturity of four-spotted megrim (Lepidorhombus boscii) between this and other studies

\begin{tabular}{|c|c|c|c|}
\hline Yazarlar & Bölge & Cinsiyet & Ilk üreme boyu $(\mathrm{cm})$ \\
\hline \multirow{2}{*}{ Papaconstantinou et al (1989) } & Euboikos körfezi (Yunanistan) & \multirow{2}{*}{$\Sigma$} & \multirow{2}{*}{20.0} \\
\hline & Pagassitikos körfezi (Yunanistan) & & \\
\hline Mannini et al (1990) & Kuzey Tyrrhenian denizi (İtalya) & $\Sigma$ & 17.0 \\
\hline \multirow{2}{*}{ Vassilopoulou et al (1997) } & \multirow{2}{*}{ Kuzeydoğu Akdeniz (Yunanistan) } & q & 13.8 \\
\hline & & $\hat{0}$ & 10.6 \\
\hline \multirow{2}{*}{ Teixeria et al (2010) } & \multirow{2}{*}{ Portekiz kıyıları } & $q$ & 18.2 \\
\hline & & $\hat{0}$ & 18.2 \\
\hline \multirow{2}{*}{$\mathrm{Bu}$ çalışma } & \multirow{2}{*}{ Saros körfezi (Türkiye) } & q & 14.9 \\
\hline & & $\hat{0}$ & 15.3 \\
\hline
\end{tabular}

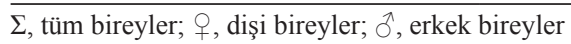


Çizelge 3- Benekli pisi balığının (Lepidorhombus boscii) bu çalışma ile önceki çalışmalarda saptanan üreme dönemlerinin karşılaştırılması

Table 3-Comparison of the spawning periods of four-spotted megrim (Lepidorhombus boscii) between this and other studies

\begin{tabular}{lll}
\hline Yazar(lar) & Bölge & Üreme zamanı \\
\hline Grubisic (1962) & Adriyatik denizi & Şubat - Mart \\
Nielsen (1986) & Kuzeydoğu Atlantik / Akdeniz & Mart - Haziran \\
Mannini et al (1990) & Kuzey Tyrrhenian denizi (İtalya) & Şubat - Nisan \\
Vassilopoulou \& Haralabous (2008) & Kuzeydoğu Akdeniz (Yunanistan) & Bahar ayları \\
Teixeria et al (2010) & Portekiz kıyıları & Kış ayları \\
Bu çalışma & Saros körfezi (Türkiye) & Şubat - Mayıs \\
\hline
\end{tabular}

\subsection{Mutlak yumurta verimliliği (fekondite)}

Mutlak yumurta verimliliği Aralık 2007 ve Şubat 2008 döneminde örneklenen 83 adet bireyden yapılmıştır. $\mathrm{Bu}$ bireylerin boyları $15.1-38.2$ (ortalama $24.8 \pm 0.65$ ) $\mathrm{cm}$, ağıllıkları ise $14.20-$ 556.41 (ortalama $162.69 \pm 14.0$ ) g. arasında değişim göstermektedir.Ortalama mutlak yumurta miktarı $56.859 \pm 4093$ adet olarak saptanmıştır. Maksimum yumurta sayısının 157.345 adet $(38.2 \mathrm{~cm} ; 556.41$ g), minimum yumurta sayısının ise 3.567 adet (15.1 $\mathrm{cm} ; 14.20 \mathrm{~g}$ ) olduğu bulunmuştur. Mutlak yumurta verimliliği - toplam boy ilişkisi $\mathrm{F}=1.487 \times \mathrm{TL}^{3.22}$ (Şekil 6); mutlak yumurta verimliliği - ağırlık ilişkisi $\mathrm{F}=264.39 \times \mathrm{W}+14.103$ (Şekil 7) ve mutlak yumurta verimliliği - yaş ilişkisi $\mathrm{F}=12.207 \times \mathrm{A}-$ 11.279 (Şekil 8) olarak tespit edilmiştir.

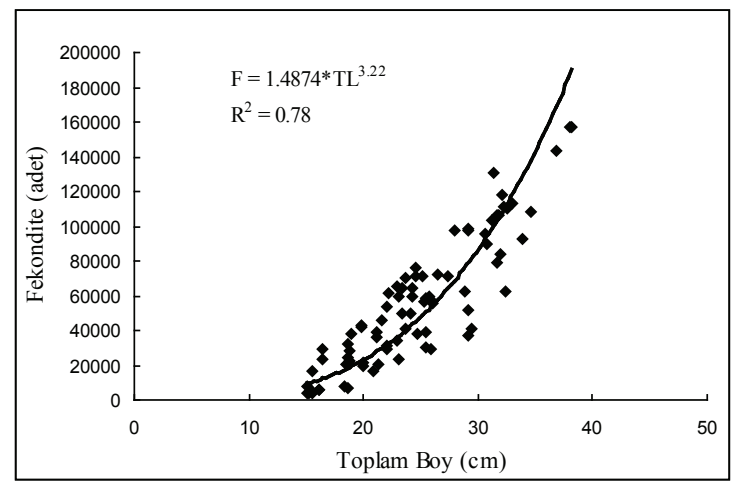

Şekil 6- Benekli pisi balığında (Lepidorhombus boscii) mutlak yumurta verimliliği - toplam boy ilişkisi

Figure 6-Absolute fecundity - total length relationship of four-spotted megrim (Lepidorhombus boscii)

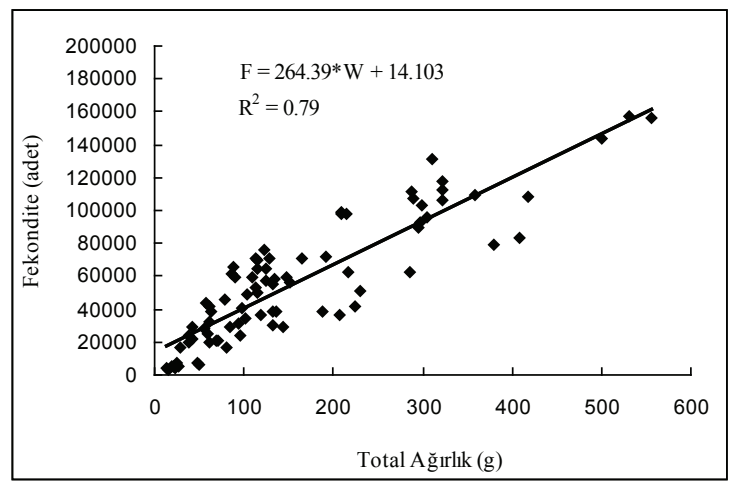

Şekil 7- Benekli pisi balığında (Lepidorhombus boscii) mutlak yumurta verimliliği - toplam ağırlık ilişkisi

Figure 7-Absolute fecundity - total weight relationship of four-spotted megrim (Lepidorhombus boscii)

Santos (1994) türün yumurta verimliliği - boy ilişkisini $\mathrm{F}=58.720 \times \mathrm{L}^{2.22}$ olduğunu, yumurta sayısının ise 42.000 ile 180.000 arasında değiştiğini saptamıştır. Birçok balık türünün yumurta verimliliği çevresel faktörler nedeniyle farklılık göstermektedir (Bircan \& Polat 1995). Dişi bir balığın yumurta verimliliği tür ve büyüklüğe bağlı olarak değişiklik göstermekle beraber, yumurta sayısı sadece türler arasında değil aynı tür içerisinde bile değişiklik gösterebilmektedir (Demirsoy 1993). Bununla beraber yumurta verimliliği, balıkların tükettiği besinlerin kalitesine ve miktarına bağlı olarak da değişebilir. Aynı zamanda, tüketilen besin miktarı arttıkça yumurta verimliliği doğru orantılı olarak artmaktadır (Avşar 2005). 


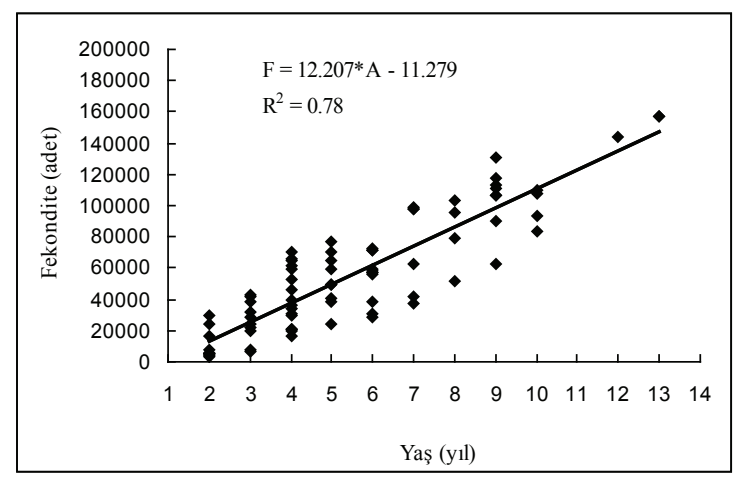

Şekil 8- Benekli pisi balığında (Lepidorhombus boscii) mutlak yumurta verimliliği - yaş ilişkisi

Figure 8-Absolute fecundity - age relationship of fourspotted megrim (Lepidorhombus boscii)

\section{Sonuçlar}

Bir balık populasyonunun devamlılığ 1 , av araçlarında yapılacak değişikliklerle beraber türe en az bir kez üreme şansı verilmesine bağlıdır. $\mathrm{Bu}$ çalışmadan önce Türkiye sularında yaşayan benekli pisi balığının üreme zamanı, ilk üreme boyu ve yumurta verimliliği konusunda bilgi olmadığından dişi ve erkek bireylerin ilk üreme boyları göz önüne alındığında, benekli pisi balığ için en küçük avlanma boyunun $16.0 \mathrm{~cm}$ olması gerektiği düşünülebilir. GSI değerlerinin kış aylarından itibaren artmaya başlaması ve Şubat-Mayıs ayları arasında da yumurtalarını bırakması dikkate alındığında, bu türün sürdürülebilirliğinin sağlanması açısından ticari avlanma yasağının aralık ayında başlatılması önerilebilir. Ayrıca, ilk üreme boyu göz önüne alınarak seçici trol av araçlarının geliştirilmesi gerekmektedir.

\section{Teşekkür}

Bu çalışma Özgür CENGIZ'in “Saroz Körfezi’ndeki (Kuzey Ege Denizi) Benekli Pisi Balı̆̆ının (Lepidorhombus boscii Risso, 1810) Populasyon Parametrelerinin Belirlenmesi" başlıklı doktora tezinin bir bölümünü içermektedir ve 106 Y035 numaralı TÜBİTAK projesi'nin desteğiyle gerçekleştirilmiş̧ir. Yazarlar yardımlarından dolayı
Adnan AYAZ ve Can Ali KUMOVA' ya teşekkür ederler.

\section{Kaynaklar}

Avşar D (2005). Balıkçılık Biyolojisi ve Populasyon Dinamiği. Nobel Yayınevi, Adana, s. 332

Bagenal T B (1978). Fecundity. In: T. B. Bagenal (ed.), Methods for Assessment of Fish Production in Fresh Waters. IBP Handbook No: 3, Blackwell Scientific, London, pp. 166-178

Bauchot M L (1987). Poissons osseux. In Fiches FAO d'identification des Especes pour les Besoins de la Peche Mediterranee et Mer Noire. Zone de Peche 37. Revision 1, vol. II.Vertebres (ed. W. Fischer et al). Rome, FAO, pp. 893-1422

Bello G \& Rizzi E (1987). On the growth of the fourspotted scaldfish, Lepidorhombus boscii, from the Southern Adriatic. FAO Fish Report 394: 142-146

Bilecenoğlu M, Taşkavak E, Mater S \& Kaya M (2002). Checklist of the marine fishes of Turkey. Zootaxa 113: 1-194

Bircan R \& Polat N (1995). Altınkaya Baraj Gölü’ndeki Capoeta capoeta (Guldenstaedt, 1773)'nın üreme mevsimi, yumurta mevsimi ve eşeysel olgunluk yaş1 üzerine incelemeler. II. Su Ürünleri Sempozyumu, Atatürk Üniversitesi, Ziraat Fakültesi Su Ürünleri Bölümü, Erzurum, pp. 287-305

Bostanc1 D \& Polat N (2008). Benekli Pisi, Lepidorhombus boscii, (Risso, 1810)'nin otolit yapıs1, otolit boyutlar1balık boyu ilişkileri ve yaş tayini. Journal of Fisheries Sciences.com 2(3): 375-381

Castilho R, Dinis M T \& Erzini K (1993). Age and growth of megrim Lepidorhombus boscii Risso off the Portuguese continental coast. Fisheries Research 16: $339-346$

Cengiz Ö, İşmen A, Özekinci U \& Öztekin A (2011). Saroz Körfezi (Kuzey Ege Denizi) balık faunası üzerine bir araştırma. Afyon Kocatepe Üniversitesi Fen Bilimleri Dergisi 11: 31-37

Cengiz Ö, Özekinci U, İşmen A \& Öztekin A (2012a). Saroz Körfezi'ndeki (Kuzey Ege Denizi, Türkiye) Benekli Pisi balığı'nın, Lepidorhombus boscii (Risso, 1810) total boy-otolit boyu arasındaki ilişki. Erciyes Üniversitesi Fen Bilimleri Enstitüsü Dergisi 28(5): 429-434

Cengiz Ö, İşmen A, Özekinci U \& Öztekin A (2012b). Saroz Körfezi'ndeki (Kuzey Ege Denizi, Türkiye) 
Kancaağız Pisi balı̆̆ı'nın, Citharus linguatula (Linnaeus, 1758), total boy-otolit boyu arasındaki ilişki. Marmara Üniversitesi Fen Bilimleri Dergisi 24(3): 68-76

Cengiz Ö, Özekinci U, İşmen A \& Öztekin A (2013). Age and growth of the four-spotted megrim (Lepidorhombus boscii Risso, 1810) from Saros Bay (Northern Aegean Sea, Turkey). Mediterranean Marine Science 14(1): 36-44

Cengiz Ö, Özekinci U, İşmen A \& Öztekin A (2014a). Saroz Körfezi'nden (Kuzey Ege Denizi, Türkiye) avlanan Benekli Pisi balığı'nın, Lepidorhombus boscii (Risso, 1810) dağılımı ve bolluğu. Adiyaman Üniversitesi Fen Bilimleri Dergisi 4(1): 27-35

Cengiz Ö, Özekinci U, İşmen A, Öztekin A \& Aslan A (2014b). Exploitation and mortalities of four-spotted megrim (Lepidorhombus boscii Risso, 1810) from Saros Bay (Northern Aegean Sea, Turkey). 1 st International Symposium on Aquatic Sciences and Technology: 15-17 May, Cyprus, pp. 67

Cengiz Ö, İşmen A \& Özekinci U (2014c). Reproductive biology of the spotted flounder, Citharus linguatula (Actinopterygii: Pleuronectiformes: Citharidae), from Saros Bay (northern Aegean Sea, Turkey). Acta Ichthyologica et Piscatoria 44(2): 123129

Demirsoy A(1993). Yaşamın Temel Kuralları Omurgalılar / Anamniyota. Cilt III / Bölüm I, Meteksan A.Ş. Bask1 Tesisleri, Ankara, s. 684

Erkoyuncu İ (1995). Balıkçılık Biyolojisi ve Populasyon Dinamiği. Ondokuz Mayıs Üniversitesi Yayınları, Sinop, s. 265

Froese R \& Binohlan C (2000). Empirical relationships to estimate asymptotic length, length at first maturity and length at maximum yield per recruit in fishes, with a simple method to evaluate length frequency data. Journal of Fish Biology 56: 758-773

Fuertes J (1978). Edad y crecimiento del gallo (Lepidorhombus boscii) en el litoral gallego. Investigaciones Pesqueras 42: 241-253

Grubisic F (1962). On the spawning period of some fishes from the central part of eastern Adriatic. Biljeske Notes 18: 1-3

Gunderson D R (1993). Surveys of Fisheries Resources. John Wiley, New York

İnnal D (2010). Population structures and some growth properties of three Cyprinid species [Squalius cephalus (Linnaeus, 1758); Tinca tinca (Linnaeus,
1758) and Alburnus escherichii (Steindachner, 1897)] living in Camkoru Pond (Ankara, Turkey). Kafkas Üniversitesi Veteriner Fakültesi Dergisi 16(Suppl-B): 297-304

Jennings S, Kaiser M J \& Reynolds J D (2001). Marine Fisheries ecology. Blackwell Science, London

JICA (1993). Marmara, Ege ve Akdeniz'de Demersal Balıkçılık Kaynakları Sörvey Raporu. Tarım ve Köyişleri Bakanlığı, Tarımsal Üretim ve Geliştirme Genel Müdürlüğü, Japonya Uluslararası İşbirliği Ajans1, s. 579

King M (1995). Fisheries Biology, Assessment and Management Fishing New Books, pp. 341

Mannini P, Reale B \& Righini P (1990). Osservazioni sulla biologia e la pesca di Lepidorhombus boscii (Risso) (Osteichthyes, Scopthalmidae) nel tirreno settentrionale. Oebalia 16(1): 245-255

Murua H, Kraus G, Saborido-Rey F, Witthames P R, Thorsen A \& Junguera S (2003). Procedures to estimate fecundity of marine fish species in relation to their reproductive strategy. Journal of Northwest Atlantic Fishery Science 33: 33-54

Nielsen J G (1986). Scophthalmidae, Fishes of the North-eastern Atlantic and the Mediterranean, ed: Whitehead P.J.P., Bauchot M.-L., Hureau J.-C., Nielsen J., Tortonese E., Vol. 3. UNESCO, Paris, pp. 1287-1293

Nikolsky G V (1963). The ecology of fishes. Academic Press, New York, pp. 352

Papaconstantinou C, Petrakis G, Mytilineou Ch, Politou C-Y, Vassilopoulou V \&Fourtouni A (1989). Fishery research on demersal fish stocks in the Euboikos and Pagassitikos Gulfs (Hellas). National Centre for Marine Research, Technical Report, Vol. I: pp. 343

Robson M S, King P A, Hannan J \& McGrath D (2000). Age and growth of a sample of four-spot megrim, Lepidorhombus boscii, from off the west coast of Ireland. Biology and Environment: Proceedings of the Royal Irish Academy 100B(3): 143-148

Santos P T (1994). Growth and reproduction of the population of the four-spot megrim (Lepidorhombus boscii Risso) off the Portuguese coast. Netherlands Journal of Sea Research 32(3-4): 379-383

Sarı E \& Çağatay M N (2001). Distributions of heavy metals in the surface of the Gulf of Saros, NE Aegean Sea. Environment International 26: 169-173 
Stergiou K I \& Politou C Y (1995). Biological parameters, body length-weight and length- height relationships for various species in the Hellenic seas. Naga (ICLARM Quarterly) 18: 42-45

Teixeirai C M, Batista M I \& Cabral H N (2010). Diet, growth and reproduction of four flatfishes on the Portuguese coast. Scientia Marina 74(2): 223-233

Wootton R J (1990). Ecology of Teleost Fishes. Chapman and Hall, Upper Saddle River, New Jersey

Wootton R J (1998). Ecology of Teleost Fishes. 2nd Edition, Kluwer Academic, London

Vassilopoulou V, Ondrias I \& Papaconstantinou C (1997). Data on the sexual maturity of the flatfish Lepidorhombus boscii (Risso) in the northeastern Mediterranean Sea (Greece). In Book of Abstracts of the American Fisheries Society 127th Annual Meeting, AFS, 24-28 August 1997, Monterey (California), pp. $42-43$
Vassilopoulou V \& Ondirias I (1999).Age and growth of the four-spotted megrim (Lepidorhombus boscii) in eastern Mediterranean waters. Journal of the Marine Biological Association of the United Kingdom 79: 171-178

Vassilopoulou V (2000). Abundance and distribution of four-spotted megrim (Lepidorhombus boscii) in the Aegean Sea. Belgium Journal of Zoology 130 (Supplement 1): 81-85

Vassilopoulou V \& Haralabous J (2008). Effects of sexual maturity and feeding on condition of a deepsea flatfish, Lepidorhombus boscii, in north-eastern Mediterranean waters. Journal of Natural History 42(5-8): 695-720

Zodiatis G \& Balopoulos E (1993). Structure and characteristics of fronts in the North Aegean Sea. Bolletino Oceanologia Teorica ed Applicata 11: 113124 